\title{
Inter-religious engagement in Malaysia: the muftis' views
}

\begin{abstract}
Islam has endorsed few ethics in dealing with the non-Muslims that reflect tolerance and compassion instead of prejudice and aversion. These ethics can be found in few Quranic verses such as verse 125 from surah al-Nahl, verse 34 from surah Fussilat and many more. It is crucial to be adopted in religiously and culturally diverse country like Malaysia. However, there are still few Muslims exhibit their antipathy and exclusive attitudes towards the non-Muslim, which hinders from Islam. This study attempts to explore muftis' views on the issue of interreligious engagement and attitudes towards the non-Muslims in Malaysia. The muftis are chosen because due to their role in the state-level religious bureaucracy and whose opinions will have a great influence on Muslims in general and three of them was a concerned in this study. Phenomenological research design was adopted for this study with in depth-interview as the main instrument. The finding suggests that all muftis demonstrate their tolerance and inclusive attitude towards the non-Muslim and they have proposed few methods in interreligious engagement such as education, akhlaq and inter-religious dialogue. The recommendations made envisaged to influence the Muslims attitude. Future research therefore should focus on the reality of inter-religious engagement among the grassroots in general.
\end{abstract}

Keyword: Mufti; Malaysia; Tolerance; Inter-religious engagement 